\title{
INNOVATION PROCESS PLANNING MODEL IN THE BPMN STANDARD
}

\author{
Magdalena JURCZYK-BUNKOWSKA
}

Opole University of Technology, Opole, Poland

e-mail: m.jurczyk@po.opole.pl

\begin{abstract}
The aim of the article is to show the relations in the innovation process planning model. The relations argued here guarantee the stable and reliable way to achieve the result in the form of an increased competitiveness by a professionally directed development of the company. The manager needs to specify the effect while initiating the realisation of the process, has to be achieved this by the system of indirect goals. The original model proposed here shows the standard of dependence between the plans of the fragments of the innovation process which make up for achieving its final goal. The relation in the present article was shown by using the standard Business Process Model and Notation. This enabled the specification of interrelations between the decision levels at which subsequent fragments of the innovation process are planned. This gives the possibility of a better coordination of the process, reducing the time needed for the achievement of its effect. The model has been compiled on the basis of the practises followed in Polish companies. It is not, however, the reflection of these practises, but rather an idealised standard of proceedings which aims at improving the effectiveness of the management of innovations on the operational level. The model shown could be the basis of the creation of systems supporting the decision making, supporting the knowledge management or those supporting the communication in the innovation processes.
\end{abstract}

Keywords: innovation process, planning, model, uncertainty, knowledge creation, Business Process Model and Notation.

\section{$1 \quad$ Introduction}

For centuries, innovations have been the most effective factor for the growth and prosperity of most organisations. A number of surveys, on how companies innovate, shows that there is a broad consensus on the need to innovate, but also widespread dissatisfaction with how innovation process is carried out [46]. Innovations create new opportunities for the organisations, however they also bring high risks of failure along. Purpose of innovation process is to compete and differentiate in market place in a successful mode [5]. Despite the creative nature of innovation process, it should be managed. As Drucker [14] noted 'innovation can be systematically managed if one knows where and how to look'. Innovation management is the invention and implementation of management practises, structures, processes which are novel and may assist business organisations to attain their goals effectively [7]. Innovations cold be 'new to the state of the art' implies management innovation without known precedents [2] or being new to the adopting organisation, i.e. new-tothe-firm $[12,48]$. At both levels of analysis, the innovation is seen as a significant departure from the past toward managerial activities and competencies that are better aligned with the competitive environment. New management practises, processes, structures and tech- niques imply changes in, respectively, the day-to-day activities of managers as part of their job in the organisation (what managers do?), the routines governing their work (how they do it?), the organisational context in which their work is performed, and the associated techniques [18]. Birkinshaw [7] noted that 'there are important similarities across the different forms of management innovation'. Innovation management encompasses all the key areas that need to be mastered to develop successful products and services, efficiently and continuously. The capacity of a firm to implement innovation management revolves around its success in dealing with these two main challenges: top-line growth and bottom-line efficiency [33]. Achieving innovation process aims could be reached through sets of management activities [8]:

- setting objectives relates to management activities to determine where the firm is going,

- motivating employees to management activities to get employees to agree to the set objectives,

- coordinating activities refers to the means by which managers organise and integrate activities of multiple groups or units,

- decision making is about making and communicating decisions regarding resource allocation. 
This article deals with the issue of innovation process planning. Planning is one of the most important manager's function. Plans are used to set directions, to reduce uncertainty, to minimise time waste and redundancy, to establish goals or standards applied in controlling the process. Properly elaborated plans should be goal-oriented and possible to complete the task, therefore constitute the basis for efficient process realisation. Can one plan processes of creative nature? This is the dilemma in the context of innovation processes. The issue of disorder in innovation processes is often rise, especially in early phases, and uncertainty connected with goal formation [38]. It is colloquially said that innovation processes are like a journey into the unknown. However it is not a lonely journey for an innovator working in his laboratory, it is rather a complex set of actions where many people are involved from both inside and outside of an organisation. Therefore achieving the desired results requires management, thus planning. The main problem of research is to show the model of innovation process planning. It has been prepared on the basis of the research on practises used in Polish companies. The model explains the very essence of the approach, which is the gradual detailing of the plans by partitioning the innovation process into phases and activities. By this way the planning is realised on three levels in detail:

- the first, establishing the ramifications of the innovation process,

- the second, related to the phase of the innovation process which is perceived as a fragment consisting in activities leading to the accomplishment of an important stage of works of a concrete aim,

- the third, related to the activity being an element of the phase of the process of the defined aim.

The plans are hierarchically interrelated to one another in such a way that the plans of a lower level are subordinate to the plans on the higher level, that is, the phase plan is dependent on the skeletal process plan and all activities included in the phase is dependent on the phase plan. The plans on particular levels bind the topdown relations which allow for the agreement between different planning levels. There are also bottom-up relations providing the feedback that is necessary for the modification of the higher level plans when conditions of the realisation of the process change. The plans on particular levels are formulated on different grades of management due to different meaning for the realization of the innovation process and different requirements as far as competence and information are concerned. Formulation of the aims of the fragments of the innovation process results from the knowledge which increases as the time passes. Therefore, the plans are prepared directly before a particular fragment at different moments of the innovation process. Planning of the innovation process combines, therefore, decisions made up at different times by different entities. Therefore, it is crucial to properly identify and describe relations between the planning levels. The present article deals the problem which can be formulated in the following way - what connections in the innovation process planning model make it possible to make up decisions dictated by the gradual increase of knowledge on one hand and, on another hand, to constantly direct the model in order to realise the process. To show the standard of these relations the Business Process Model and Notation has been proposed. It is the standard developed by the Object Management Group (OMG) which provides an easily understandable notation for defining business processes. The primary goal of BPMN was to provide a notation that is readily understandable by all business users, from the business analysts who create the initial draught of the processes, the technical developers responsible for implementing the technology that will support the performance of those processes, and finally, the business people who will manage and monitor those processes [50].

The basis for the development of the innovation process planning model constituted the bibliography research as well as empirical investigation. In the following sections of the article, the fundamental elements of the theory of the management of innovations to relate the problem of innovation process planning are presented. Section 3 shows the methodology of the empirical research as well as the main conclusions. In Section 4 the core of the innovation process planning model is depicted. Section 5 shows relations between elements of the innovation process planning model using the BPMN notation. The last section contains concluding remarks on the use of the model in managing innovations. 


\section{Planning in management of the innovation process}

The effective implementation of innovation has gained an increasing level of recognition as synonymous with constructing sustained competitive advantage thereby boosting organisational performance [31]. Within an ever more competitive environment, innovation proves a critical factor both for companies attempting to retain dominant positions and for raising profit levels $[19,29]$. Various authors point out innovation as the only route to companies adapting to increasingly dynamic surrounding environments [20, 42].

\subsection{Specifics of innovation processes}

Activities realised in order to convert the invention into a commercial product or service, for that innovation makes the processes. It means that they proceed in a certain order following each other and also that mutually interrelated by certain changes they cause. Pavitt claims that innovation processes differ considerably between companies and that they are also directed according to the way they function which is largely dependent on the special field [41]. Nowadays it is commonly assumed that innovation processes are not structuralised to a great extend and that the models developed are only guidelines which should be flexibly adapted to a particular situation. One can find the claims that innovation processes are the antithesis to the linear activity [44]. For instance, Bujis underlines that the innovation process is a set of different, parallel, competitive and conflicting processes which take place at the same time [11]. The innovation process consists of stages which can be ordered and bound with each other with different interactions. A division of three phases is commonly assumed. These phases are: generating ideas, the development of the concept and the commercialisation [10]. Within these phases there are lots of activities that are realised. Kline and Rosenberg stress that the process of innovation should not be considered linearly in the sense that solving one problem leads to the formulation of another one. Instead, different problems are solved at the same time as a result of interaction, feedbacks and the coordination between different activities in the chain [30].

The feature which disallows the use of the methods of managing the project during the entire innovation process is the lack of its purpose. Realising the set of mutually interrelated actions the entrepreneur aims at providing the knowledge for a particular area. However, he does not know what the final effect of the activities will be. Also, $\mathrm{He}$ does not know how long the process is going to last. Hence, the innovation processes are labelled as a journey into the unknown [49], without determined parameters such as cost, time and quality.

\subsection{Knowledge management in innovation process}

Creation of knowledge drives the innovation process and hence it is commonly reflected upon within this notion. Individual organisations as part of the global economy are exposed to an international environment of fierce competitiveness where survival relies on the speed of innovation. The ability to manage knowledge is becoming increasingly more crucial in today's knowledge economy and it all begins with generation of knowledge. Knowledge management is a term which relates to the systematised specification of the ramifications: communicating, intercepting, acquiring and organising both the covert and the overt knowledge. The aim is to enable all employees to use the knowledge even more effectively and efficiently and, what follows, to maximise the resources of knowledge [4]. Knowledge management encompasses creating, distributing, storaging and using of knowledge. The management is used to create a collective wisdom in order to increase the flexibility and innovation of an organisation [16]. Fostering the process of knowledge creation is the first step to facilitating innovations in a company. Each participant of the innovation process is engaged in creating knowledge. According to the SECI model [40], its separate fragments spread within the team and the entire business. It forms, then, the basis for the use of knowledge as well as for the creation of new fragments of knowledge. As it is stated in Jorna [23], knowledge is a basic source of innovation, which is engaged in realisation of the innovation process and is the result of the innovation process. Knowledge management seen at the angle of the realisation of the innovation processes is to lead to the gradual increase of knowledge and being directed on realising common goals of a given business. 


\subsection{Uncertainty in innovation processes}

The uncertainty exists if a given situation is unclear and complicated, when information is missing or incoherent as well as when people feel uncertain as to their own knowledge or a state of knowledge in general [9]. The most difficult case of uncertainty takes place when there is no immediate reason for cause-reaction state, the lack of conformity between interrelated parts and difficulties in identification of appropriate sources of information [17]. Such uncertainty takes place in the case of a new and totally unpredictable activity [43]. In a similar manner it is stated in Spash [45] where he talks about a strong uncertainty in a situation where one cannot predict the results of past events, but also when one cannot predict which events will result in changes in the future. Uncertainty, then, is a state of uncomfortable for managers as they do not know how to act in a given situation. Therefore, most people seem to avoid it [28]. In innovation processes there is often an impasse caused by a cycle of mutual awaiting for a decision which separate members of a team those who do not want to make. On the basis of literature review, there are eight factors creating uncertainty in the innovation process: technological uncertainty, market uncertainty, regulatory uncertainty, social and political uncertainty, acceptance and legitimacy uncertainty, managerial uncertainty, timing uncertainty and consequence uncertainty [22].

\subsection{Planning of innovation processes}

Planning is the process which sets the directions of action and makes decisions based on facts, aims and appropriately thought-over estimations. The very core of creating plans is orientation of all activities on previously assumed aims and their coordination. The aim of processes of innovation is gradually specified along with the increase of knowledge about a given notion. Because of this, by setting up the process one cannot specify the actions and their order of performance according to which they should be constrained in order to finalise the process. Because of this, one can often turn to specifying the intermediate goals, but without plans the works would proceed in a chaotic way which would, in effect, result in a worse effectiveness. The plan is the basic tool of coordination. Therefore, one must assume that without it the entrepreneur is going to expect the benefits in a longer period of time than in the case when he/she prepares the innovation process plan.

The realisation of separate activities and the way of doing so results from effects of previously accomplished actions. It is an argument speaking for the fact that innovation process planning should be accomplished in a way that is not traditional. Using the standard approach to plan and control leads to a failure which comes from a too radical formalisation. The formalisation itself delimits creativity as well as flexibility that is necessary while reacting to the changes of the surrounding $[1,6,35]$.

The processes of innovation are so complicated and dynamic that planning innovations should be made a basic element of managing for companies willing to develop in such way. Nevertheless, the features of the innovation process mentioned above are the basis of argumentation according to which planning cannot be effective [36, 37]. At the same time there is an articulated fact that even preparing the initial plan guarantees keeping the realisation direction on the right track and provides guidelines for the realisation of such a complex undertaking [32]. Moreover, as was noticed by Lonergan and Mumford [34, 39], in the case when the situations are poorly defined which are characteristic to a creative thinking, people tend to doubt and choose more reliable, familiar, less risky and less innovative solutions. From such a perspective the plan constitutes the guiding point leading to more innovative solutions than in the case if it was missing [3].

One of the main problems of each company is the allocation of resources [15]. Without planning and comparing the expectations to the strategy of a company there is a possibility of losing them in an endless process of generating ideas. To prevent this, the plan is to specify the conditions according to which the progress from the ideas generation phase to distribution and conception development phase takes place. This forms the condition for the realisation of the profit in the process of innovation [38]. Moreover, planning is an element that helps a given company to learn and hence it is one of the most important elements of the innovation process. One needs to notice that due to high risk, they often end with failures [21]. However, the extensive experience and knowledge in a given company is often cited as a benefit of such a process. The plan allows for the analysis of causes of failures and successes, which considerably enriches knowledge of a given business in a long-term perspective. 


\section{$3 \quad$ Research methodology}

The aim of the research was to determine how innovation processes are planned, how managers realise this task considering the uncertainty of the aim and essential actions and resources. In order to find regularities, one has to consider innovation process management as integrity. This will require the analysis of planning examples, their evaluation, generalisation of observations and formulation of rules. Therefore the method of direct interview was chosen as the most adequate.

\subsection{Research project}

Proper research was conducted using preliminary analysis. It was done on the basis of literature as well as on case study type analysis of different innovative projects in a medium sized IT company. Several projects of various meaning and novelty degree were analysed. During preliminary research all the observations enabled to hypothesise and formulate the direct interview questionnaire. The choice of the research attempt was imposed by the will of finding proper planning mechanisms. Thus it was decided to conduct the research in those companies which realize innovation processes and achieve satisfying effects. The companies were selected from Polish innovation ranking leaders. So as to formulate general rules, observations were made in companies of different sizes and branches. Mediumsized companies, which employed approximately 100 people, constituted the biggest percentage among those which agreed to take part in the research $(\sim 50 \%)$.

\subsection{Data gathering}

Every interview referred to several examples of innovations conducted in the space of 2-3 years. Its aim was to compare the approach toward innovation planning regarding the character of the process. The analysed examples of innovation processes were characterised by various novelty degree, scope of changes and meaning for the enterprise. They concerned innovations of different types, however the majority related to product innovations (ca. 60\%). The research was successfully conducted in 32 companies; over 100 examples of innovation processes were analysed. The examples were selected based on the evaluation of managers who were asked to discuss those processes which, in their opinion, ended successfully. The interviewers concentrated on gaining information, nevertheless also referred to other managerial functions.
The interviews lasted on average $1.5 \mathrm{~h}$ and were conducted with people directly managing the processes and also with board members of the enterprise. Despite preliminary assumption, not many companies possessed documentation related to innovation process planning.

\subsection{Research conclusions}

Conducted research led to a number of conclusions which were the basis for formulating the assumptions of innovation process planning model. The most important conclusion was the fact that plans are created gradually; it enables managers to use the gradually collected knowledge. That is why the plan of the whole process is not created at its beginning. Only its realisation frames are set and within those frames and further decisions are made concerning logic fragments of the process such as stages and actions. These decisions are made directly before commencing a particular fragment. It is compliant with Du Preez's [13] statement that in order to improve the innovation management process, it is wise to break the whole process into smaller stages of activity. This helps to guide and focus on activities, especially the information generation and collection activities. A staged approach therefore simplifies the management of the innovation process by providing clear management decision points. This ensures better control of the process in terms of time and quality. Progressing task realisation leads to specification of given aims, it can be, therefore, stated that planning is dynamic. All decisions are made referring to current knowledge and forecast. It should also be noted that realisation of innovation process depends on company's resources. Competences are the most important among the resources. The use of external resources is frequent while executing particular process fragments and it is also determined by the company's possibilities. Thus managers, while making planning decisions, on the one hand consider the requirements describing the expectations toward process effects. On the other hand they take into account the possibilities describing expenses for achieving those effects. To sum up, a manager who creates and plans can only gradually analyse the situation with the progress that is with the creation of new knowledge. The lack of knowledge constraints the planning, as it is shown on Figure 1. While passing between symbolic points, one makes further decisions and clearly sees the aim. 


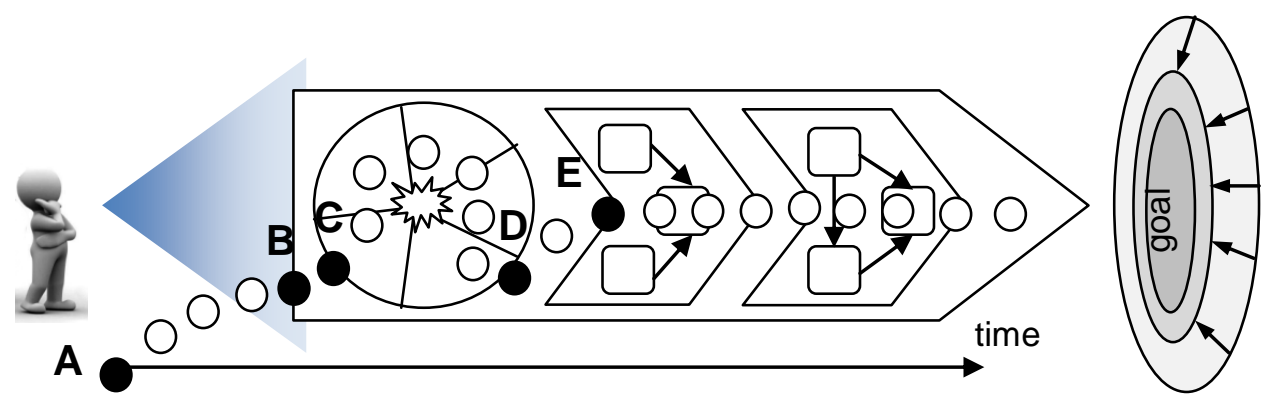

Figure 1. Option of formulating planning problems

Point A, the beginning of an innovation process, is a place where decisions are made about the limits. In point $B$ the manager refers to the first phase of the innovation process. It is in point $\mathrm{C}$ that detailed decisions are made concerning actions. In the presented example it can be idea generation or opportunity identification, depending on the impulse which provoked the innovation process. Hence passing from point to point unknown number of times in an unknown sequence, particular actions of front-end phase are planned. Only after achieving the assumed result, which is being in point $\mathrm{D}$, one has the accurate knowledge to elaborate plans for development phase. This phase is more structured, however, recurrences and repetitions of certain actions cannot be excluded.

\section{Concept of planning innovation processes}

The model compiled as a result of research carried on in the previous chapter points to the components of planning the processes of innovation as well as describes the interrelations between them. It is proposed to look at the innovation process at the angle of the knowledge created, what its importance for the company is and how to plan its creation. At the moment of initiating the innovation process one cannot specify its aim and, as a result, to determine its course. Therefore, it is impossible to create the plan in its entirety. On the other hand, if one wants to follow a particular direction, to reasonably allocate resources, coordinate the works, coordinate the course of the process one needs to have a plan. Hence, the solution is to separate fragments of the innovation process and providing plans for them with compliance to decisions for the entire innovation process. It is possible only as a result of a trial and error method. From this perspective, the problem has been stated as follows: which fragments of innovation processes should be formulated in order for decisions related to them could be undertaken including the created knowledge and the changes of the surrounding. At the same time it should be specified which structure of plans guarantees both the stimulation of the progress of works in a given direction and the coordination providing, at the same time, flexibility allowing for the introduction of creative solutions and the reaction to the results obtained.

\subsection{Assumptions of innovation process planning model}

The innovation process is undertaken in order to obtain particular profits which are to be vital for the company's development. The development of a company can be realised by traditional and innovative solutions. The company decides to use the innovative process if they expect a better effect (e.g. more permanent or significant change). The effect of the innovation process can be a product, a process, a marketing method or an organisational method. Undertaking the innovation process, the entrepreneur estimates if he/she has an access to right resources. The company which realise innovation processes make use of internal resources and, if it is possible, external resources. Within the surroundings of the company there are constant changes whose influence has to be included in the plans of the innovation processes. In the innovation process the level of uncertainty decreases considerably along with the progress of works [47]. Therefore, there is no need of making detailed decisions ahead of time. The phases of the innovation process follow in a strict order. They are sets of activities which aim at obtaining a particular effect which is a vital point during the realisation of the innovation process. Knowledge is created during each phase and is necessary for the initiation of another phase. It is, then, vital to specify the criteria of the evaluation of the end of each phase. Activities within the framework of a given phase can take place simultaneously, in a parallel fashion. 


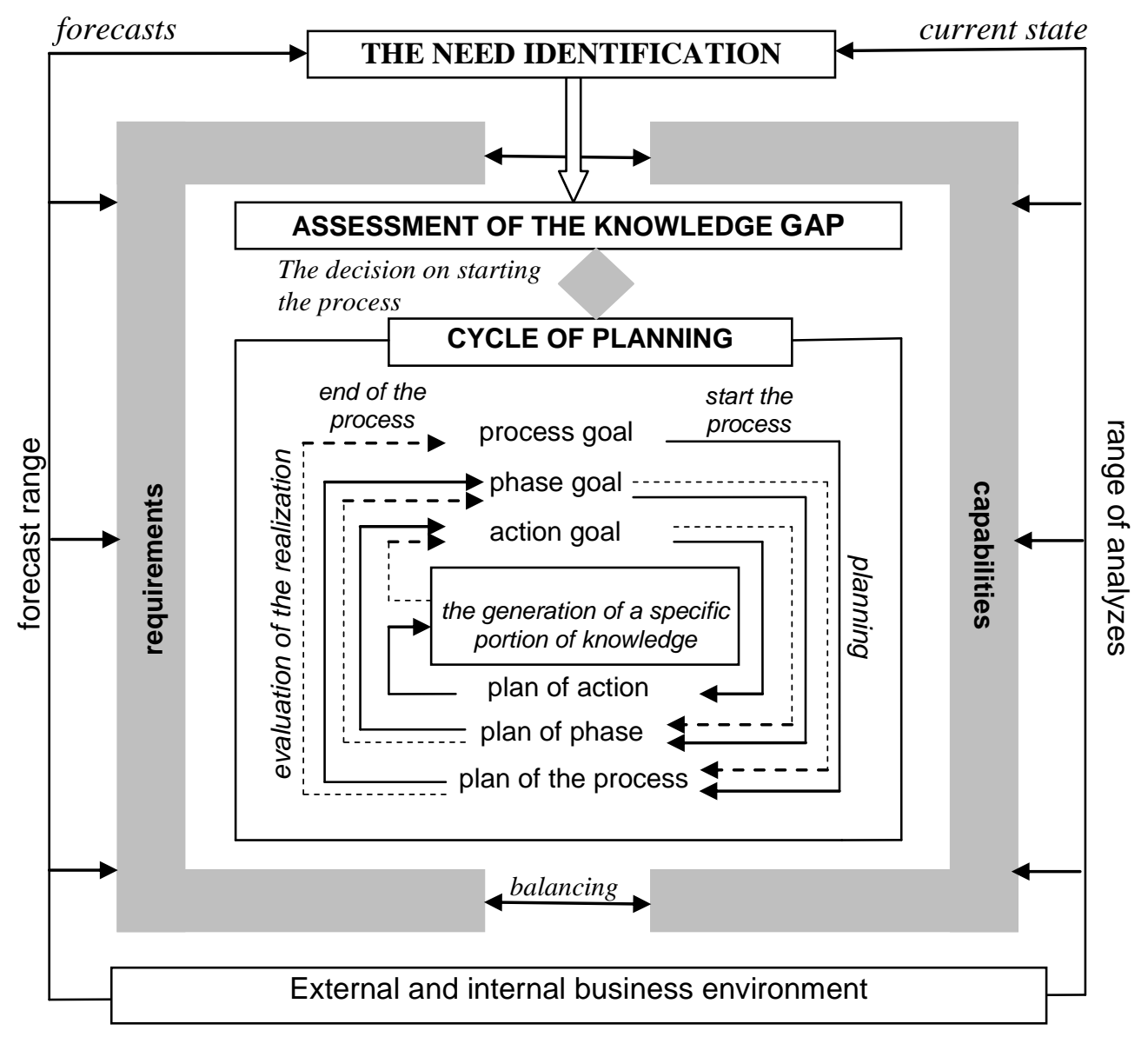

Figure 2. Scheme of the innovation process planning model

They are the set of activities which are bound by a common goal. It describes a part of knowledge which is to be created as a result of an activity. The activities in the innovation process are often experimental in nature. Therefore, the effects of their realisation are often not known in advance. The effects can determine the undertaking of subsequent, previously unpredicted works. The activities which lead to obtaining a given effect can be repeated even several times and realised in different ways. One needs to specify the criteria describing a satisfactory effect of their completion. In the case when the effects are not met the innovation process can be stopped or given up.

\subsection{The essence of innovation process planning model}

In order to meet the presented requirements, the model assumes the sequence of the process of the plans creation. It is a gradual and successive (along with knowledge creation) transition from generally formulated plans (guidelines), to detailed planning decisions. The model specifies the dependences between subse- quent levels of planning and shows what the basic elements of decisions that were made. Figure 2 provides the scheme of the model with the connections between plans of different fragments of the innovation process together with elements basic for the planning decisions.

The outer square symbolises the surrounding of the company. Thanks to predicting of the surrounding changes trends the needs determining the development of the company are identified. The external surrounding constitutes the requirements and the internal situation delimits the possibilities of fulfilling these requirements. The identification of the need is the impulse to consider the undertaking of a particular innovation process. The final decision about whether to develop a particular area of the company functioning in a traditional or innovative way will be constrained by the wish of the entrepreneur to take the risk and follow a different, more innovative and risky route of development.

Balancing between requirements and possibilities constitutes ramifications for the entire planning process. Not only does it determine whether the innovation 
process will be initiated, but it also specifies its entire course which is the basis for formulating plans of all innovation process fragments. Specifying the current state and the requirements related to fulfilling a certain need provides the possibility of assessment of the gap in knowledge which disallows a given company from implementing the innovation. Such a diagnosis rests on subjective values expressed in the linguistic form, therefore, it has been suggested to carry it on the basis of the fuzzy logic [24]. The value obtained in this way gives the basis for an ultimate decision of whether to take up the realisation of the innovation process which will require creating and implementing a certain amount of knowledge to the company, or not.

The fragment placed at the centre of Figure 2 shows the recurrent procedure in compiling plans related to the realisation of the innovation process. It is the planning cycle which encapsulates taking planning decisions, their creation and estimation of the effects. It rests on the successive formulation of indirect goals and providing plans for their realisation. As noted above, it is only at the point of relation to actions can the goal be precisely formulated. Such a precise formulation will ensure that the plans due to their specificity can be termed as executive.

Goals and plans of the fragments of the innovation process are hierarchically interrelated in order to reach the assumed goal in a stable manner and to fulfil the identified need. It means that the skeletal plan of the process is the basis for more detailed plans of the process phases. The phases, in turn, specify the possibilities during the formulation of the plans of activities. Realising the activity allows for acquiring of knowledge necessary for planning and initiating another activity. Such a process is repeated until the end of the phase, that is, the realisation of all the activities leading to its completion. Knowledge gained as a result of the completion of a phase is the basis for the estimation of the plans of another phase within which another group of activities will be planned and realised.

\section{$5 \quad$ Relations in innovation process planning model}

In order to show the relations between levels of planning a standard BPMN was used. The notation inherits and combines elements from a number of previously proposed notations for business process modelling, including the XML Process Definition Language (XPDL) and the Activity Diagrams component of the
Unified Modelling Notation (UML). Like these predecessors, a key idea of BPMN is that process models are composed of:

- activity nodes, denoting business events or items of work performed by humans or by software applications,

- control nodes capturing the flow of control between activities.

Activity nodes and control nodes can be connected by means of a flow relation in almost arbitrary ways. Furthermore, BPMN brings additional features not traditionally associated with graph-oriented languages. These features include the ability to define:

- subprocesses that may be executed multiple times concurrently,

- subprocesses that may be interrupted as a result of exceptions,

- message flows between processes.

The modelling of business processes often starts with capturing high-level activities and then drilling down to lower levels of detail within separate diagrams. BPMN utilises the concept of pools as a mechanism to organise activities into separate visual categories in order to illustrate different functional capabilities or responsibilities. Pools are used when the diagram involves two separate business entities or participants and are physically separated in the diagram. It was used showing the planning cycle of the innovation process (see Figure 3), which is realised at three levels representing the stages of the decisions made:

1) Company management where general plans are formulated. These plans form the framework for the innovation process. Also, the most important decisions such as stopping the realisation of the process, cooperation with external units, etc. are made.

2) The level of the leader of the process where phase realisation plans are formulated as well as the decisions concerning initiation of subsequent activities are made.

3) The executive level where the way in which a given activity is going to be performed is specified. Also, some detailed decisions concerning its realisation such as allocation of resources, initiation moment are made at this level. 


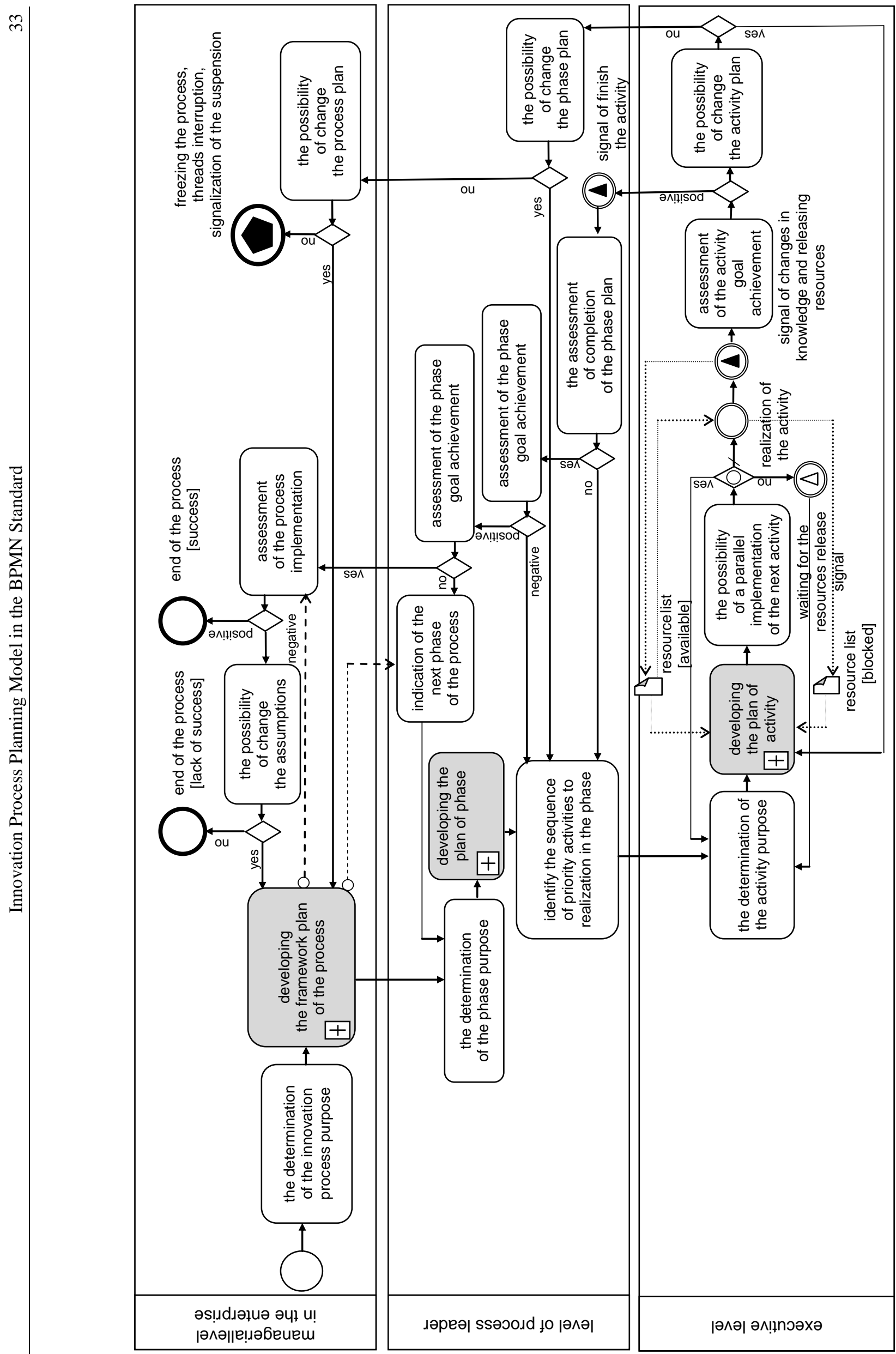

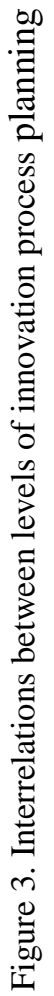




\subsection{Interrelations between decisions of first level of planning}

The planning process at the first level begins by providing the scheme for the innovation process. It is formulated in a general way showing innovative areas as well as effects which should be met at this area. Even due to such unspecific assumptions, it is possible to formulate the guidelines acting as frameworks for realising the process as a whole. They are, however, very general, which allows a flexible creation of plans of smaller fragments of the process. The smaller fragments take into account the surrounding changes as well as the knowledge acquired.

Decisions made in this area are superior to the subsequent planning levels. The compilation process of these plans is marked by the block in Figure 3. Expanding it into the scheme of the planning decisions at the first level as shown in Figure 4, where the most frequently appearing sequence of decisions is depicted. It also shows the information used for its undertaking.

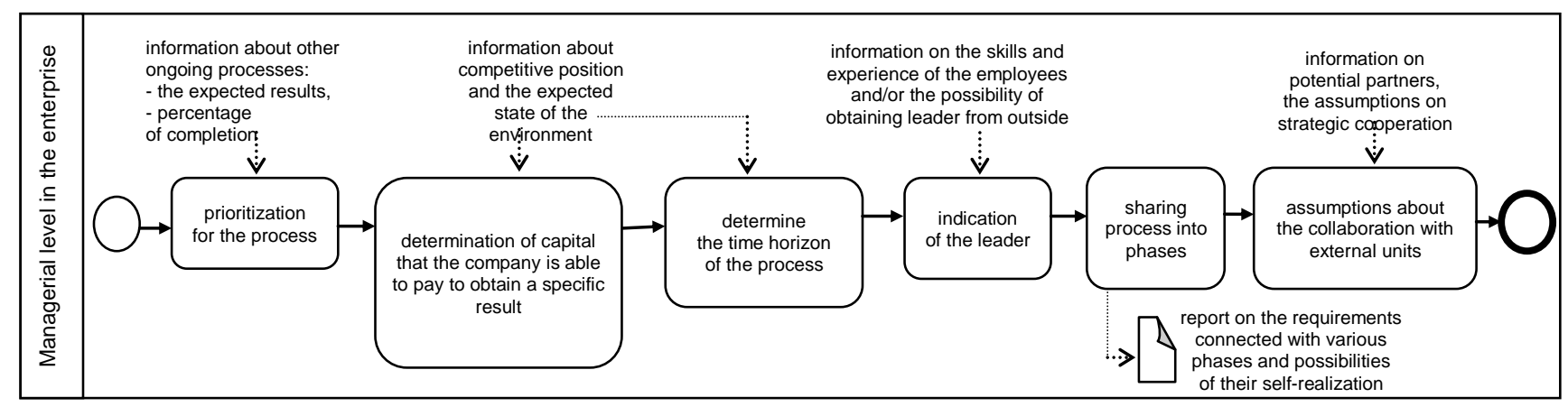

Figure 4. Compiling the framework plan of innovation process

\subsection{Relations between decisions at second level of planning}

The phase of the innovation process represents its crucial fragment leading to the completion of one stage of the process and allowing for the initiation of another. If at the first level of planning one assumed the division of a given process into three phases, the plans will have to be formulated three times at the second level. It follows immediately after defining the goal for each phase, that is, at different moments of the innovation process. The planning procedure at the second level starts from specifying the effect that the realisation of a given phase has to reach. From the planning procedure result key actions that have to be undertaken to reach this effect. Specifying the plans being directives for the phases of realisation one depicts among other things the level of the technical advancement, compatibility with solutions used, the effect on the natural environment, etc.

At the level of planning of a leader of the process one makes decisions concerning the cooperation with external units. The range of works entrusted to the external unit as well as additional arrangements (e.g. about the communication method) are being specified. On Figure 5 which shows the scheme of interrelations at the second level of planning one included the option of such cooperation.

\subsection{Relations between decisions at third level of planning}

Phases in the process of innovation follow each other consecutively. This does not include, however, the actions included in the phase range. Due to the parallelism of realisations of actions, the planning procedure at the third level is performed dynamically. Specifying the goal of the realisation of the activity is dependent on the results of the previous actions within the framework of a given process fragment. Therefore, the plans are formulated directly before the beginning of the activity. Specifying the goal of the realisation of the activity is dependent on the results of the previous actions within the framework of a given process fragment. Therefore, the plans are formulated directly before the beginning of the activity. The problem connecting the second and third level of planning is the question from which action to begin in order to get the highest possible efficiency of the use of resources. The proceedings in this case somewhat resembles a system of 'squeezing' which is known for steering the flow of production. 


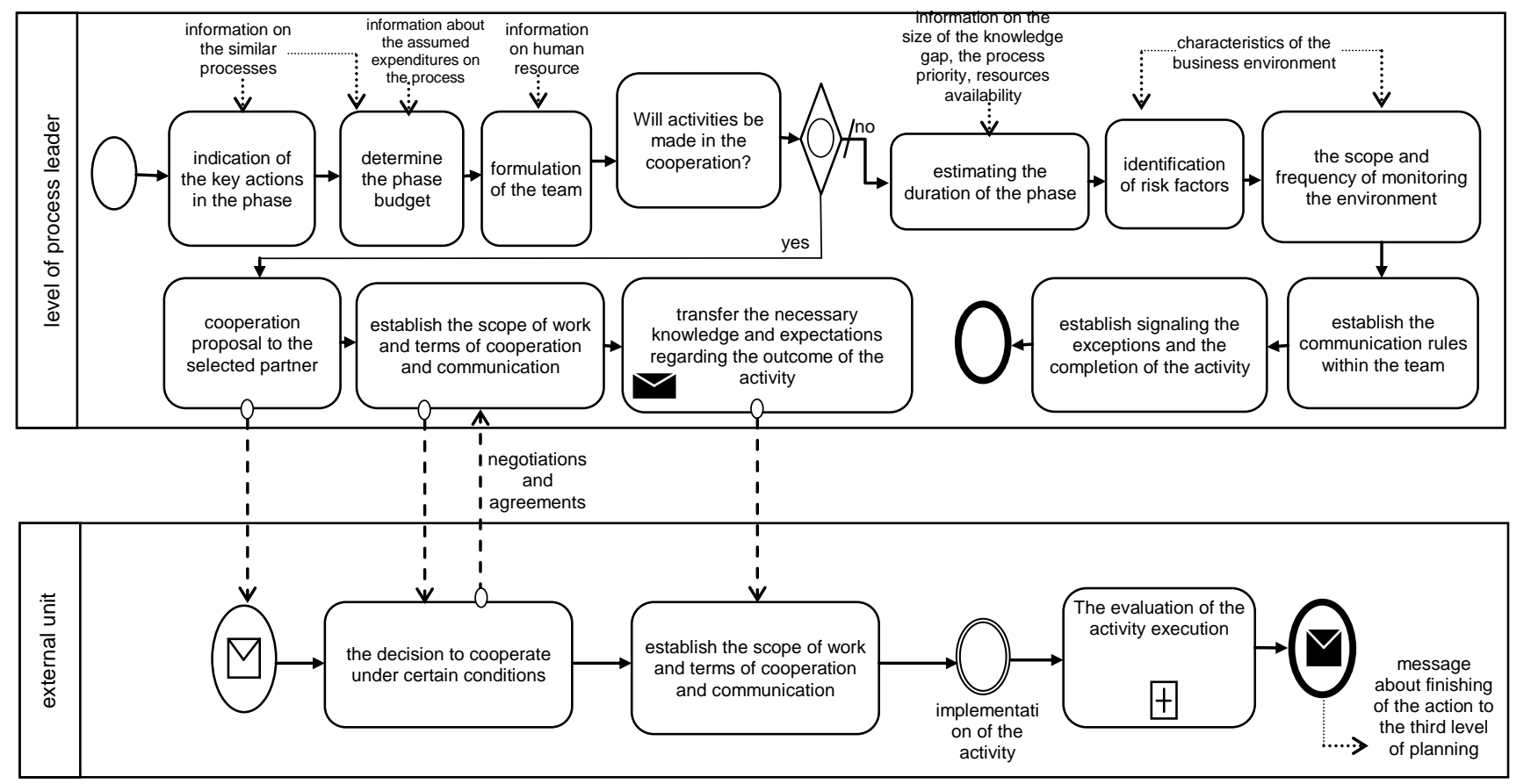

Figure 5. Relations in planning phases of innovation processes including cooperation with external units

It is suggested to start planning by indicating the sensitive fragment of knowledge that should be generated in a given phase. These can be activities associated with the highest costs, longest time or the most risky ones. They can also be those that create most unique knowledge. Such action delimits the realisation of the process from the standpoint of achieving the intended effect of the phase - its purpose. Not only do the works leading directly to the key fragment of knowledge can be undertaken immediately after initiating a given phase. The planning procedure begins then from those which have to preceded the undertaking of this crucial activity. Focusing on the chain of activities to achieve the desired outcome organises the planning procedure in the execution phase. This allows for the coordination of works and selecting those whose realisation affects the goal of the realisation of the phase and the time of its completion. The scheme of interconnections on the executive level is presented in Figure 6.

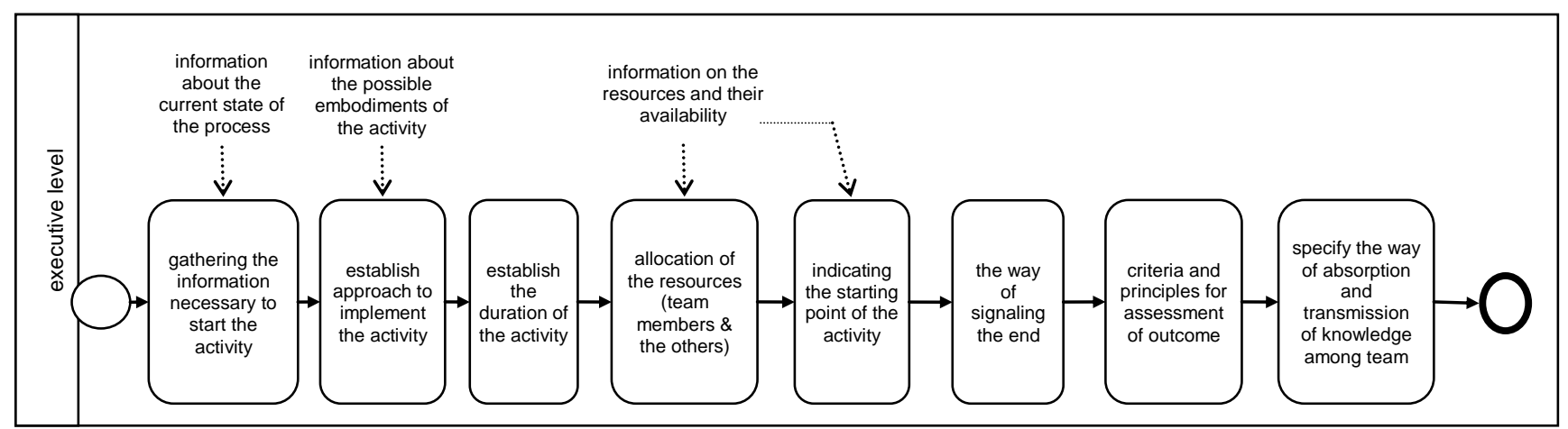

Figure 6. Interrelations between decisions at the executive level of planning

The approach presented gives a considerable freedom of the executor of the activity and allows using creative solutions. On the other hand, knowing the plan, the leader can control the course of its realisation. As was noted by one of responders such approach influences the work progress and improves the engage- ment of the team. The ideas for reaching a given goal of the activity can be discussed in a group, which solidifies the cooperation in a team and influences the creation of knowledge. 


\section{Conclusions}

The model is a simplified and idealised way of showing the phenomenon being researched. It can refer to real standards, but also to potential and ideal systems. In this case, the model of planning the innovation processes combines so to say the two approaches. Real practises functioning in companies have been generalised and idealised, therefore, creating a coherent entirety which presents the philosophy of planning the innovation processes. The important aspect of this model is the guarantee of the convergence of the successively compiled plans of the fragments of the innovation process with the need determining the development of the company. Hence, the model is a path on which the manager can move in a way that is best for him/her. Following this path the manager makes use of the experiences, thanks to which he/she can avoid particular mistakes and errors which play a major role in failures in realising the innovation processes. A general assumption differentiating the presented model from approaches such as Stage-Gate or Innovation Funnel was the concentration on the area having the influence on the development of the company. Such identified needed the ideas of innovative solutions are generated. In other publications a different approach to establish this need with respect to different management horizons [25] was presented. Also, the approach toward eliciting fragments for which the plans are formulated [27] was offered. One noted also the issue of the estimation of the capabilities for the realisation of the innovation process by a given organisation [24] as well as the approach toward the analysis allowing for the decision making on different levels of planning [26].

In this article the author focussed on the interrelations between the levels of planning which are to integrate the intermediate goals as well as decisions for their completion. The presentation of the most important relations in the BPMN standard allows for the translation of the compiled standards into practise. This is important for the preparation of the planning system in particular companies where the model is going to improve the efficiency of management of innovation processes. Preparation of the set of algorithms made it possible to also verify the model itself. The BPMN standard turned out to be clear in a way that made it possible to prepare an analysis of subsequent steps of planning without any problems even by people who had not been previously familiarised with the modelling of processes.

The innovations are compiled and implemented with the future in mind. They result, therefore, from the estimations which are often taken to contain errors and the degree of uncertainty. It complicates the planning procedure which has to be dynamic in order to enable reactions to unpredictable notions. The question may be asked: is not using the model an oversimplification? Researching this problem one has stated that the effectiveness of managers in managing the processes of innovation is mainly the ability of an adaptive creation of plans. Thanks to a gradual planning one may obtain a significant flexibility as well as the adaptation to the changes of the surrounding as well as the successive knowledge acquisition.

In order to obtain considerable profits from using such approach the advanced abilities of self-organisation of teams are, however, required. It is the element of the innovation culture which should be developed constantly. Organisations have different capabilities in this respect and, hence, the interrelations between levels of planning shown above should have more or less formal character. Formally, the relations guarantee the effectiveness of interrelations between levels of planning. The relations between levels of planning presented in the article can be the basis for the projecting the procedures of acting in different situations. Due to the high level of uncertainty and low precision of the plans the further researches should focus on stating the mechanisms of the control and steering of innovation processes.

Acknowledgement

The project funded by the National Science Center in the scope of the research project No. 4025/B/H03/2011/40 Fri: "Developing a model of planning and estimating the cost of innovation".

\section{Bibliography}

[1] Abbey A., Dickson J. - R\&D work climate and innovation in semiconductors [in] Academy of Management Journal, No.25, 1983, pp. 362-368.

[2] Abrahamson E. - Management fashion [in] Academy of Management Review, No. 21, 1996, pp. 254-285. 
[3] Adams J.E., Day G.S. - Enhancing new product development performance: An organizational learning perspective [in] Journal of Product Innovation Management, No15, 1998, pp. 403-422.

[4] Alavi M., Leidner D.E. - Review: Knowledge Management and Knowledge Management Systems: Conceptual Foundations and Research Issues [in] MIS Quarterly, 2001, Vol. 25, No.1, pp. 107-136.

[5] Baregheh A., Rowley J. \& Sambrook S. - Toward a multidisciplinary definition of innovation [in] Management Decision, Vol. 47, No. 8, 2009, pp. 1323-1339.

[6] Bart C.K. - Controlling new product $R \& D$ projects [in] R\&D Management, 1993, No 23, pp. 187-197.

[7] Birkinshaw J., Hamel G. \& Mol M.J. - Management Innovation [in] Academy of Management Review, Vol. 33, No. 4, 2008, pp. 825-845.

[8] Birkinshaw J. - Reinventing Management: Smarter Choices for Getting Work Done. Chichester: John Wiley and Sons.2010.

[9] Brashers D.E. - Communication and Uncertainty Management [in] Journal of Communication, No. 51, 2001, pp. 477-497.

[10] Buckler S.A. - The Spiritual Nature of Innovation [in] Research Technology Management, , Vol. 40, No. 2, 1997, pp. 43-47.

[11] Buijs J. - Modelling Product Innovation Process, from Linear Logic to Circular Chaos [in] Creativity and Innovation Management, Vol. 12, No. 2, 2003, pp. 76-93.

[12] Damanpour F., Walker R.M. \& Avellaneda C.N. Combinative effects of innovation types and organizational performance: A longitudinal study of service organizations [in] Journal of Management Studies, No. 46, 2009, pp. 650-675.

[13] Du Preez N.D. \& Louw L. - A framework for managing the innovation process. Cape Town: PICMET, 2008.

[14] Drucker P.F. - The discipline of innovation [in] Harvard Business Review, November - December, Vol. 76, No. 6, 1998, pp. 149-157.

[15] Estrin J. - Closing the innovation gap. New York, NY: McGraw-Hill, 2009.

[16] Frappaolo C. - Implicit knowledge [in] Knowledge Management Research \& Practice, Vol. 6, No. 1, 2008, pp. 23-25.
[17] Gales L., Mansour-Cole D. - User involvement in innovation projects: Toward an information processing model [in] Journal of Engineering Technology Management, No. 12, 1995, pp. 77109.

[18] Hollen R., Van Den Bosch F. \& Volberda H.W. The Role of Management Innovation in Enabling Technological Process Innovation: An InterOrganizational Perspective [in] European Management Review, No. 10, 2013, pp. 35-50.

[19] Hu J.L., Hsu Y.H. - The more interactive, the more innovative? A case study of South Korean cellular phone manufacturers [in] Technovation, No. 28, 2008, pp. 75-87.

[20] Hua S.Y., Wemmerlov U. - Product change intensity, product advantage, and market performance: an empirical investigation of the $P C$ industry [in] Journal of Product Innovation Management, No. 23, 2006, pp. 316-329.

[21] Hurley R.F., Hult T.M. - Innovation, market orientation, and organizational learning: An integration and empirical examination [in] American Marketing Association, No.3, 1998, pp. 42-54

[22] Jalonen H., Lehtonen A. - Uncertainty in the innovation process [at] Proceedings of ECIE 2011 The 6th European Conference on Entrepreneurship and Innovation, Aberdeen, 2011.

[23] Jorna R.J. - Sustainable innovation: The organizational, human and knowledge dimension. Sheffield: Greenleaf Publishing, 2006.

[24] Jurczyk-Bunkowska M. - Characteristics of decisive problems in innovation process planning [at] Proceedings of the 14th European Conference on Knowledge Management, 5-6 September 2013, Kanuas, Lithuania (in print).

[25] Jurczyk-Bunkowska M., Jungowski K. - Solutions for innovation management system: approach based on Theory of Constraints [at] Proceedings of the 12th International CINet Conference: Doing More with Less. Aarhus, Denmark, September 2011, pp. 425-435.

[26] Jurczyk-Bunkowska M. - Environmental scanning as an element of innovation process planning: context of management horizons [at] Strategic Management Society (SMS) 32nd Annual International Conference, Prague, Czech Republic, October 7-9, 2012. 
[27] Jurczyk-Bunkowska M. - Model of innovation process planning based on research of polish enterprises [at] Proceedings of the 13th International CINet Conference, Roma, Italy, pp. 616-627, 2012.

[28] Kaasa A., Vadi M. - How does culture contribute to innovation? Evidence from European countries [in] Economics of Innovation and New Technology, Vol. 19, No. 7, 2010, pp. 583-604.

[29] Kamiński P. de Oliveira A. \& Lopes T. Knowledge transfer in product development processes: a case study in small and medium enterprises (SMEs) of the metal mechanic sector from São Paulo, Brazil [in] Technovation, No. 28, 2008, pp. 29-36.

[30] Kline S.J., Rosenberg N. - An Overview of Innovation. In Landau \& Rosenberg, The Positive Sum Strategy. National Academy Press, Washington DC. 1986, pp. 275-304.

[31] Koc T., Ceylan C. - Factors impacting the innovative capacity in large - scale companies. Technovation, No. 27, 2007, pp. 105-104.

[32] Latham G.P., Locke E.A. - Self-regulation through goal-setting [in] Organizational Behavior and $\mathrm{Hu}-$ man Decision Processes, No. 50, 1991, pp. 212247.

[33] Liyanage S. \& Poon P.S. - Technology and innovation management learning in the knowledge economy [in] The Journal of Management Development, Vol. 22, No. 7/8, 2002, pp. 579-602.

[34] Lonergan D.C., Scott G. M.\& Mumford M.D. Evaluative aspects of creative thought: Effects of idea appraisal and revision standards [in] Creativity Research Journal, No.16, 2004, pp. 231-246.

[35] Miller C., Osburn R.N. - Multi-level issues in creativity and innovation [in] M.D. Mumford, Hunter S. T., Bedell-AversK. E. (ed.): Research in multilevel issues, Oxford, UK: Elsevier, 2008, s. 169187.

[36] Mintzberg H., Raisinghani D., Theoret A. - The structure of unstructured decision processes. [in] Administrative Science Quarterly, No. 21, 1976, pp. 246-275.

[37] Mintzberg H. - Learning-1, Planning-0 - Reply. [in] Strategic Management Journal, No.12, 1991, pp. 463-466.
[38] Mumford M.D., Bedell-Avers K.E., Hunter S.T. Planning for innovation: A multi-level perspective [in] Mumford M.D., Hunter S.T., Bedell-AversK. E. (ed.): Research in multi-level issues, Oxford, UK: Elsevier, 2008, pp. 107-154.

[39] Mumford M.D., Blair C., Dailey L., Lertiz L.E., Osburn H.K.: Errors in creative thought? Cognitive biases in a complex processing activity [in] Journal of Creative Behavior, No 40, 2006, pp. 75109.

[40] Nonaka I., Takeuchi H. - The Knowledge-Creating Company. Oxford: Oxford University Press, 1995.

[41] Pavitt K. - The Process of Innovation (Working paper). Sussex, UK: The Freeman Centre, University of Sussex, 2003

[42] Roberts P.W., \& Amit R. - The dynamics of innovative activity and competitive advantage: the case of Australian retail banking, 1981 to 1995 [in] Organization Science, Vol. 14, No. 2, 2003, pp. 107 122

[43] Sartorius C. - Second-order sustainability - conditions for the development of sustainable innovations in a dynamic environment [in] Ecological Economics, No 58, 2006, pp. 268-286.

[44] Schroeder R., Van de Ven A., Scudder G., Polley, D.E. - Managing Innovation and Change Processes: Findings from the Minnesota Innovation Research Program. Agribusiness, Vol. 2, No. 4, 1986, pp. 501-523

[45] Spash C. - Greenhouse Economics: Values and Ethics, Routledge, New York 2002.

[46] Trías de Bes F., Kotler P. - Winning At Innovation: The A-to-F Model, Basingstoke [England]: Palgrave Macmillan, 2011.

[47] Trott P. - Innovation Management and New Product Development. Prentice Hall, 2005.

[48] Vaccaro I.G., Jansen J.J., Van Den Bosch F.A. \& Volberda H.W. - Management innovation and leadership: The moderating role of organizational size [in] Journal of Management Studies, No. 49, 2012, pp. 28-51.

[49] Van de Ven A., Polley D.E., Garud R., Venkataraman S. - The Innovation Journey, Oxford University Press, 1999.

[50] White S.A. - Introduction to BPMN. IBM Cooperation, 2004. 